\title{
KEAKURATAN SOLUSI PADA PERSAMAAN DIFUSI MENGGUNAKAN SKEMA CRANK-NICOLSON
}

\author{
Afidah Karimatul Laili' ${ }^{1}$, Ari Kusumastuti² \\ ${ }^{1}$ Mahasiswa Jurusan Matematika, Fakultas Sains dan Teknologi, UIN Maulana Malik Ibrahim Malang \\ ${ }^{2}$ Dosen Jurusan Matematika, Fakultas Sains dan Teknologi, UIN Maulana Malik Ibrahim Malang \\ e-mail: aphid.laili@gmail.com arikususmastuti@gmail.com
}

\begin{abstract}
ABSTRAK
Persamaan difusi adalah persamaan diferensial parsial linier yang merupakan representasi berpindahnya suatu zat dalam pelarut dari bagian berkonsentrasi tinggi ke bagian yang berkonsentrasi rendah. Penelitian ini bertujuan untuk menentukan distribusi temperatur persamaan difusi dengan menggunakan skema Crank-Nicolson. Pertama, mendiskritisasikan persamaan difusi menggunakan skema Crank-Nicolson. Diskritisasi akan menghasilkan matriks. Selanjutnya menentukan kestabilan dan konsistensi. Kestabilan dan konsistensi untuk menunjukkan bahwa metode yang digunakan tersebut memiliki solusi yang dapat mendekati solusi analitiknya sehingga diketahui bahwa solusi tersebut akurat. Matriks hasil diskritisasi akan disimulasikan dalam program. Hasil simulasi menunjukkan bahwa distribusi temperatur menurun terhadap waktu karena adanya perpindahan panas.
\end{abstract}

Kata kunci: solusi akurat, persamaan Difusi, perpindahan panas balik, Skema Crank-Nicolson.

\begin{abstract}
Diffusion equation is a linear differential equation that represents the transfer of substance from the high concentration part to the lower concentration part. This research is determine the temperature distribution of diffusion equation using Crank-Nicholson scheme. First, Discretization diffusion equation using Crank-Nicholson scheme. Obtained from the discretization is matrix. Next, determining stability and consistency. The stability and consistency to indicate that the method used have a solution that can be approximating analytical solution so known regularization. Matrix discretization results will be simulated in the program. The simulation results show that the temperature distribution decreases with time to heat transfer.
\end{abstract}

Keywords: regularization, Diffusion equation, backward heat equation, Crank-Nicholson Scheme.

\section{PENDAHULUAN}

Estimasi error adalah suatu proses yang bertujuan untuk mencari solusi terbaik dengan mempertimbangkan besarnya nilai error yang dihasilkan dengan metode numerik. Dalam prosesnya, estimasi error didapatkan dari ekspansi daret Taylor yang dipotong setelah suku turunan yang diinginkan. Dengan pemotongan order yang ke n, maka hasil perhitungan akan mendekati solusi. Jadi dalam estimasi error akan dihasilkan suatu solusi yang akurat. Solusi akurat yaitu dekatnya suatu solusi pendekatan terhadap nilai sebenarnya.

Dalam prosesnya, dibutuhkan suatu metode numerik yang akan menghasilkan solusi pendekatan terbaik. Solusi pendekatan salah satunya adalah skema Crank-Nicolson. Skema
Crank-Nicolson adalah pengembangan dari metode beda hingga skema eksplisit dengan metode beda hingga maju skema implisit. Namun bentuk dari skema Crank-Nicolson adalah skema implisit. Kelebihan metode ini dibandingkan dengan metode beda hingga yang lain adalah stabil tanpa syarat.

Penelitian terdahulu oleh (Durmin, 2013) telah meneliti tentang perbandingan solusi dari skema implisit dan skema Crank-Nicolson untuk model perpindahan panas. Fokus penelitian (Durmin, 2013) adalah membandingkan solusi dari skema implisit dan skema Crank-Nicolson dengan cara simulasi.

Penelitian terdahulu oleh (Le, Q.H., \& Nguyen, 2013) meneliti tentang keakuratan solusi pada persamaan perpindahan panas balik dengan menggunakan ketaksamaan. Pada hasil 
diperoleh dengan error yang relatif kecil dan mendekati solusi sesungguhnya. Dengan telah diketahuinya bahwa telah didapatkan error yang relatif kecil, penulis ingin mengetahui estimasi error pada persamaan yang sama dengan metode yang berbeda pada penentuan solusi pendekatannya.

Pada penelitian ini diselesaikan persamaan difusi menggunakan skema Crank-Nicolson, dalam penyelesaiaannya dilakukan diskritisasi menggunakan metode beda hingga skema CrankNicolson, kemudian menentukan syarat kestabilan dan menentukan syarat konsistensi untuk mengetahui bahwa hasil diskritisasi tersebut akurat. Selanjutnya melakukan simulasi dari skema yang digunakan dan interpretasi hasil.

\section{KAJIAN PUSTAKA}

\section{Persamaan Difusi}

Persamaan difusi yang dipakai adalah persamaan perpindahan panas balik

$$
\begin{gathered}
\frac{\partial u}{\partial t}(x, t)-a(t) \frac{\partial^{2} u}{\partial x^{2}}(x, t)=f(x, t), \\
u(0, t)=u(\pi, t)=0, \\
u(x, 1)=g(x)=\frac{\cos (1) \sin (x)}{\exp \left(1^{2}+1\right)}
\end{gathered}
$$

dengan domain $t \in[0,1], x \in[0, \pi], a(t)$ adalah fungsi $2 t+1$, dengan solusi eksak $u(x, t)=$ $\frac{\cos (t) \sin (x)}{\exp \left(t^{2}+t\right)}$, serta $\quad f(x, t)=-\frac{\sin (t) \sin (x)}{\exp \left(t^{2}+t\right)} \cdot u(x, t)$ adalah fungsi distribusi temperatur dan $u(x, 1)$ adalah distribusi temperatur awal, $u_{t}$ adalah variabel panas yang bergantung pada $t, u_{x x}$ adalah variabel panas yang bergantung pada $x$, dan $a(t)$ adalah konstanta panas (Le, Q.H., \& Nguyen, 2013).

\section{Skema Crank-Nicolson}

Skema Crank-Nicolson merupakan salah satu skema pengembangan dari skema eksplisit dan implisit, yaitu merupakan nilai rerata darai kedua metode tersebut. Pada skema Crank-Nicolson diferensial terhadap waktu $t$ dituliskan dalam bentuk beda maju, yaitu (Triatmodjo, 2002)

$$
\frac{\partial u(x, t)}{\partial t}=\frac{u_{j}^{n+1}-u_{j}^{n}}{\Delta t}
$$

Sedangkan, diferensial terhadap ruang $x$ merupakan rerata dari skema eksplisit dam implisit dengan menggunakan beda pusat

$$
\frac{\partial u(x, t)}{\partial x} \approx \frac{1}{2}\left(\frac{u_{j+1}^{n}-u_{j-1}^{n}}{\Delta x}+\frac{u_{j+1}^{n+1}-u_{j-1}^{n+1}}{\Delta x}\right)
$$

Untuk diferensial orde 2 terhadap waktu dapat dituliskan sebagai berikut

$$
\begin{aligned}
\frac{\partial^{2} u(x, t)}{\partial x^{2}}= & \frac{1}{2}\left(\frac{u_{j-1}^{n+1}-2 u_{j}^{n+1}+u_{j+1}^{n+1}}{\Delta x^{2}}\right)+ \\
& \frac{1}{2}\left(\frac{u_{j-1}^{n}-2 u_{j}^{n}+u_{j+1}^{n}}{\Delta x^{2}}\right)
\end{aligned}
$$

\section{Keakuratan Solusi}

Keakuratan solusi numerik diukur berdasarkan kriteria konvergensi, konsistensi serta stabilitas. Konvergensi berhubungan dengan besarnya penyimpangan solusi pendekatan oleh metode beda hingga terhadap solusi eksak. "Aproksimasi solusi pasti konvergen ke solusi analitiknya, jika konsistensi dari persamaan beda dan stabilitas dari skema yang diberikan terpenuhi (Zauderer, 2006)". Kriteria stabilitas dan konsitensi merupakan kondisi perlu dan cukup agar diperoleh solusi konvergen.

Analisis kestabilan dari skema yang digunakan dapat dicari menggunakan stabilitas Von Neumann dengan mensubstitusikan $u_{j}^{n}=$ $\rho^{n} e^{i a j}$ ke dalam persamaan beda yang digunakan, sedangkan untuk analisis konsistensi dapat dicari dengan menggunakan ekspansi deret Taylor. Syarat perlu dan cukup stabilitas Von Neumann yaitu $|\rho| \leq 1$ dan kriteria konsistensi akan terpenuhi jika $\Delta x \rightarrow 0$ dan $\Delta t \rightarrow 0$. Jika syarat kestabilan dan konsistensi terpenuhi maka solusi numerik tersebut akan mendekati solusi analitik (Zauderer, 2006).

\section{PEMBAHASAN}

\section{Solusi Persamaan Difusi dengan Skema Crank-Nicolson}

Persamaan difusi yang digunakan adalah persamaan (1) yang akan dianalisis dengan skema Crank-Nicolson (Durmin, 2013). Mengacu pada persamaan (4), maka bentuk diskrit dari persamaan (1) adalah sebagai berikut:

$$
\begin{aligned}
& \frac{u_{j}^{n+1}-u_{j}^{n}}{\Delta t}- \\
& \frac{1}{2}\left(a^{n} \frac{u_{j-1}^{n}-2 u_{j}^{n}+u_{j+1}^{n}}{\Delta x^{2}}+\right. \\
& \left.a^{n} \frac{u_{j-1}^{n+1}-2 u_{j}^{n+1}+u_{j+1}^{n+1}}{\Delta x^{2}}\right)=f_{j}^{n}
\end{aligned}
$$

Kemudian untuk semua variabel dengan superskrip $n$ dikelompokkan ke ruas kanan, sehingga 


$$
\begin{aligned}
-\left[\frac{a^{n}}{2 \Delta x^{2}}\right] u_{j-1}^{n+1}+ & {\left[\frac{1}{\Delta t}+\frac{a^{n}}{\Delta x^{2}}\right] u_{j}^{n+1}-} \\
& {\left[\frac{a^{n}}{2 \Delta x^{2}}\right] u_{j+1}^{n+1}=} \\
& {\left[\frac{a^{n}}{2 \Delta x^{2}}\right] u_{j-1}^{n}+} \\
& {\left[\frac{1}{\Delta t}-\frac{a^{n}}{\Delta x^{2}}\right] u_{j}^{n}+} \\
& {\left[\frac{a^{n}}{2 \Delta x^{2}}\right] u_{j+1}^{n}+f_{j}^{n} }
\end{aligned}
$$

diasumsikan sebagai:

$$
\begin{aligned}
& A_{j}=C_{j}=D_{j}=F_{j}=\frac{a^{n}}{2 \Delta x^{2}} ; \quad B_{j}=\frac{1}{\Delta t}+\frac{a^{n}}{\Delta x^{2}}, \\
& E_{j}=\frac{1}{\Delta t}-\frac{a^{n}}{\Delta x^{2}},
\end{aligned}
$$

sehingga persamaan di atas dapat ditulis kembali sebagai:

$$
\begin{gathered}
-A_{j} u_{j-1}^{n+1}+B_{j} u_{j}^{n+1}-C_{j} u_{j+1}^{n+1}= \\
D_{j} u_{j-1}^{n}+E_{j} u_{j}^{n}+ \\
F_{j} u_{j+1}^{n}+f_{j}^{n}
\end{gathered}
$$

Kemudian untuk $n=1,2, \ldots, M-1$ dan $j=$ $1,2, \ldots, M$. Misalkan $M=5, M$ adalah banyaknya iterasi, maka pada persamaan (7) akan diperoleh suatu matriks,

$$
\left[\begin{array}{ccccc}
B_{1} & C_{1} & \cdots & 0 & 0 \\
A_{2} & B_{2} & \cdots & 0 & 0 \\
\vdots & \vdots & & \vdots & \vdots \\
0 & 0 & \cdots & B_{M-2} & C_{M-2} \\
0 & 0 & \cdots & A_{M-1} & B_{M-1}
\end{array}\right]\left[\begin{array}{c}
u_{1}^{n+1} \\
u_{2}^{n+1} \\
\vdots \\
u_{M-2}^{n+1} \\
u_{M-1}^{n+1}
\end{array}\right]=\left[\begin{array}{c}
D_{1} \\
D_{2} \\
\vdots \\
D_{4} \\
D_{5}
\end{array}\right]
$$

maka matriksnya $A u_{j}^{n+1}=D_{j}$, dimana $A$ dan $B$ adalah matriks tridiagonal dengan ukuran $(M-1) \times(M-1)$ dan unsur $u_{j}^{n}$ dan $f_{j}^{n}$ diketahui dan selesaiannya adalah $u_{j}^{n+1}=$ $A^{-1}\left(D_{j}\right)$ yang berukuran $(M-1) \times 1$.

\section{Keakuratan Solusi Hasil Skema Crank- Nicolson}

Untuk Menunjukan bahwa persamaan (5) bernilai benar dan memiliki solusi yang dapat mendekati solusi analitik, maka cukup dengan menunjukan bahwa persamaan beda yang digunakan tersebut stabil dan konsisten. mengetahui apakah metode yang digunakan untuk mendekati persamaan difusi tersebut stabil atau tidak, maka uji kestabilan dapat dilakukan menggunakan analisa stabilitas Van Neumann, dengan cara mensubstitusikan $u_{j}^{n}=$ $\rho^{n} e^{i a j}, \forall i=\sqrt{-1}$ ke dalam persamaan (5) yang terlebih dahulu dikalikan dengan $\Delta \mathrm{t}$, sehingga diperoleh persamaan sebagai berikut:

$$
\begin{aligned}
& u_{j}^{n+1}-u_{j}^{n}= \\
& \left(a^{n} \Delta t \frac{u_{j-1}^{n}-2 u_{j}^{n}+u_{j+1}^{n}}{2 \Delta x^{2}}+\right. \\
& \left.a^{n} \Delta t \frac{u_{j-1}^{n+1}-2 u_{j}^{n+1}+u_{j+1}^{n+1}}{2 \Delta x^{2}}\right)+\Delta t f_{j}^{n}
\end{aligned}
$$

Kemudian dapat dicari dengan cara mensubstitusikan $u_{j}^{n}=\rho^{n} e^{i a j}, \forall i=\sqrt{-1} \quad$ ke dalam persamaan tersebut dan $\Delta t f_{j}^{n}$ dianggap kecil , sehingga:

$$
\begin{aligned}
& \rho^{n+1} e^{i a j}-\rho^{n} e^{i a j}= \\
& \frac{a^{n} \Delta t}{2 \Delta x^{2}}\left(\rho^{n} e^{i a(j-1)}-2 \rho^{n} e^{i a j}+\right. \\
& \left.\rho^{n} e^{i a(j+1)}\right)+ \\
& \frac{a^{n} \Delta t}{2 \Delta x^{2}}\left(\rho^{(n+1)} e^{i a(j-1)}-2 \rho^{(n+1)} e^{i a j}+\right. \\
& \left.\rho^{(n+1)} e^{i a(j+1)}\right)
\end{aligned}
$$

Untuk penyederhanaan, persamaan (10) dibagi dengan $\rho^{n} e^{i a j}$, misalkan $a^{n}$ diasumsikan sebagai $k$ sehingga diperoleh:

$$
\rho=\frac{1+\frac{k \Delta t}{2 \Delta x^{2}}\left(e^{-i a}-2+e^{i a}\right)}{\left[1-\frac{k \Delta t}{2 \Delta x^{2}}\left(e^{-i a}-2+e^{i a}\right)\right]}
$$

Karena $e^{ \pm i a}=\cos a \pm i \sin a$, maka persamaan (11) dapat ditulis:

$$
\rho=\frac{1+\frac{k \Delta t}{2 \Delta x^{2}}(\cos a-i \sin a-2+\cos a+i \sin a)}{\left[1-\frac{k \Delta t}{2 \Delta x^{2}}(\cos a-i \sin a-2+\cos a+i \sin a)\right]}
$$

sehingga diperoleh:

$$
\rho=\frac{1+\frac{k \Delta t}{2 \Delta x^{2}}(2 \cos a-2)}{\left[1-\frac{k \Delta t}{2 \Delta x^{2}}(2 \cos a-2)\right]}
$$

Misalkan $\frac{k \Delta t}{2 \Delta x^{2}}=S$

$$
|\rho|=\sqrt{\left[\frac{1+S(2 \cos a-2)}{[1-S(2 \cos a-2)]}\right]^{2}}
$$

Persamaan stabil jika dan hanya jika $|\boldsymbol{\rho}|<\mathbf{1}$ atau 


$$
\frac{1+4 S(\cos a-1)}{1-4 S(\cos a-1)} \leq 1
$$

Karena $-2 \leq \cos a-1 \leq 0$, maka persamaan (14) terpenuhi untuk setiap $S \in R$. Sehingga didapatkan kestabilan dari persamaan difusi menggunakan skema Crank-Nicolson adalah stabil tanpa syarat.

Setelah diperoleh syarat kestabilan maka selanjutnya syarat konsistensi, untuk mengetahui skema yang digunakan konsisten atau tidak, dapat dilakukan dengan ekspansi deret Taylor yang disubstitusikan kedalam persamaan (5). Ekspansi deret Taylor yang digunakan adalah sebagai berikut:

$$
\begin{gathered}
u_{j}^{n \pm 1}=u_{j}^{n} \pm\left.\Delta t u_{t}\right|_{j} ^{n}+\left.\frac{1}{2} \Delta x^{2} u_{t t}\right|_{j} ^{n} \pm \\
\left.\frac{1}{6} \Delta t^{3} t t t\right|_{j} ^{n}+\cdots \\
u_{j \pm 1}^{n \pm 1}=u_{j}^{n} \pm\left.\Delta t u_{t}\right|_{j} ^{n} \pm\left.\Delta x u_{x}\right|_{j} ^{n}+ \\
\frac{1}{2}\left(\left.\Delta t^{2} u_{t t}\right|_{j} ^{n}+\right. \\
\left.2 \Delta t \Delta x u_{t x}\right|_{j} ^{n}+ \\
\left.\left.\Delta x^{2} u_{x x}\right|_{j} ^{n}\right)+ \\
\frac{1}{6}\left(\left.\Delta t^{3} u_{t t}\right|_{j} ^{n}+\right. \\
\left.3 \Delta t^{2} \Delta x u_{t t x}\right|_{j} ^{n}+ \\
\left.3 \Delta t \Delta x^{2} u_{t x x}\right|_{j} ^{n}+ \\
\left.\left.\Delta x^{3} u_{x x x}\right|_{j} ^{n}\right)+\cdots \\
\left.\frac{1}{6} \Delta x^{3} u_{x x x}\right|_{j} ^{n}+\cdots \\
u_{j \pm 1}^{n}=u_{j}^{n} \pm\left.\Delta x u_{x}\right|_{j} ^{n}+\left.\frac{1}{2} \Delta x^{2} u_{x x}\right|_{j} ^{n} \pm \\
\\
\\
\\
\\
\end{gathered}
$$

Selanjutnya substitusikan persamaan (15), (16) dan (17) kedalam persamaan (5), dengan sedikit manipulasi aljabar maka diperoleh persamaan berikut:

$$
\begin{aligned}
& \left.\left(u_{t}-\frac{a^{n}}{2} u_{x x}-\frac{a^{n}}{2} u_{x x}-f\right)\right|_{j} ^{n}+ \\
& \left.\left(\frac{1}{2} u_{t t}-\frac{a^{n}}{\Delta x}-8 a^{n} \Delta x^{3} u_{t x x x}\right) \Delta t\right|_{j} ^{n}- \\
& \left.\frac{a^{n}}{6} u_{x x x} \Delta x\right|_{j} ^{n}+ \\
& \left.\left(\frac{1}{6} u_{t t t}-12 a^{n} \Delta x^{2} u_{t t x x}\right) \Delta t^{2}\right|_{j} ^{n}- \\
& \left.\frac{a^{n}}{12} u_{x x x x} \Delta x^{2}\right|_{j} ^{n}+\cdots=0
\end{aligned}
$$

Suku pertama pada persamaan (18) adalah persamaan difusi yang telah diselesaikan. Suku kedua dan seterusnya adalah suku tambahan yang didapatkan dari penyelesaian menggunakan persamaan beda hingga dan disebut truncation error. Truncation error atau galat pemangkasan yang didapatkan adalah

$$
\begin{aligned}
\left.\left(\frac{1}{2} u_{t t}-\frac{a^{n}}{\Delta x}-8 a^{n} \Delta x^{3} u_{t x x x}\right) \Delta t\right|_{j} ^{n}- & \\
& \left.\frac{a^{n}}{6} u_{x x x} \Delta x\right|_{j} ^{n}+ \\
& \left(\frac{1}{6} u_{t t t}-\right. \\
& \left.12 a^{n} \Delta x^{2} u_{t t x x}\right)\left.\Delta t^{2}\right|_{j} ^{n}- \\
& \left.\frac{a^{n}}{12} u_{x x x x} \Delta x^{2}\right|_{j} ^{n}+\cdots
\end{aligned}
$$

Karena $\Delta x$ dan $\Delta t$ sangat kecil maka jumlah dari limit tersebut akan semakin kecil, karena berapapun nilai $u_{t t}, u_{t x x x}$ dan $u_{x x x}$ jika dikalikan dengan nilai dari $\Delta t$ dan $\Delta x$ akan semakin kecil. Error pemotongan yang dihasilkan akan menuju nol untuk $\Delta x \rightarrow 0$ dan $\Delta \mathrm{t} \rightarrow 0$. Jadi skema CrankNicolson konsisten terhadap persamaan difusi.

\section{Simulasi dan Interpretasi Hasil}

Persamaan yang digunakan dalam simulasi adalah persamaan (7) yang merupakan bentuk diskrit dari persamaan difusi. Dalam simulasi digunakan $\Delta x=0,0698$ dan $\Delta t=0,0222$, sehingga simulasi persamaan difusi dapat dilihat pada gambar (1) berikut: 


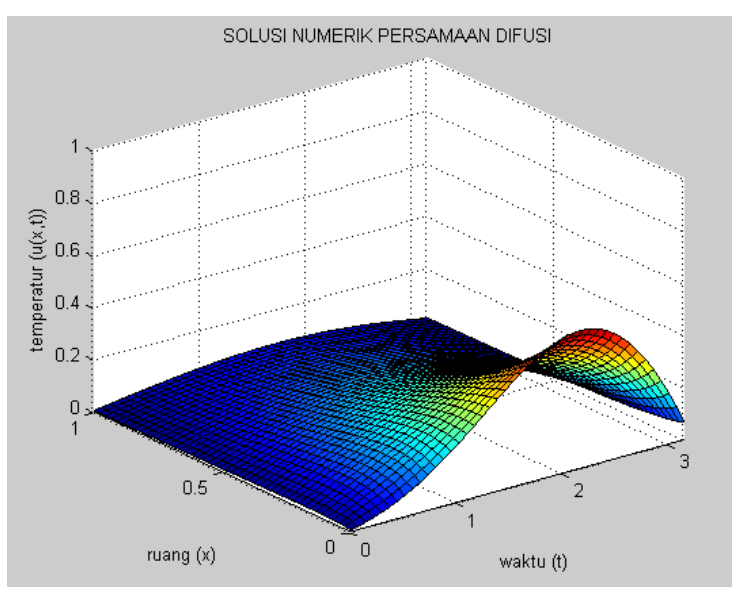

Gambar 1. Solusi Numerik Persamaan Difusi Menggunakan Skema Crank-Nicolson

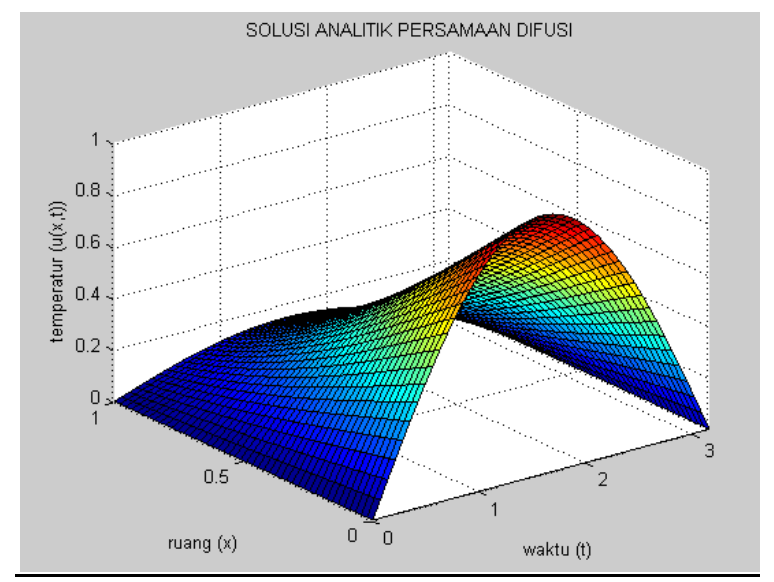

Gambar 2. Solusi Analitik Persamaan Difusi

Pada Gambar 1 solusi numerik di atas perubahan temperatur berjalan dari $x=0$ di $t$ berapapun berada pada temperatur $u(x, t)=0$ kemudian berjalan naik sampai pada temperatur tebesar yaitu pada $x=1,827$ dan $t=0$ dengan temperatur $u(x, t)=0,4855$ kemudian berjalan turun sampai pada $x=\pi$ di $t=0$ dengan temperatur $u(x, t)=0$. Pada Gambar 2 solusi analitik di atas perubahan temperatur berjalan secara sama yaitu dari $x=0$ di $t$ berapapun berada pada temperatur $u(x, t)=0$ kemudian berjalan naik sampai pada temperatur tebesar yaitu pada $x=1,536$ dan $t=0$ dengan temperatur $u(x, t)=0,977$ kemudian berjalan turun sampai pada $x=\pi$ di $t=0$ dengan temperatur $u(x, t)=0$.

Perubahan temperatur pada solusi numerik dan solusi analitik bergerak secara sama. Perubahan temperatur terjadi secara signifikan yaitu pada ruang $x=0$ dengan temperatur yang awal nya kecil $u(x, t)=0$ kemudian perlahan mengalami kenaikan sampai pada ruang tengah $x$. Kemudian temperatur $u(x, t)$ mengalami penurunan secara terus menerus sampai pada ruang $x$ maksimal. Perubahan temperatur tersebut berjalan secara sama di $t$ berapapaun

\section{KESIMPULAN}

Berdasarkan hasil pembahasan, dapat diperoleh kesimpulan antara lain:

1. Hasil diskritisasi skema Crank-Nicolson pada persamaan difusi stabil pada saat $\Delta t$ dan $\Delta x$ berapapun, karena skema Crank-Nicolson. Hasil diskritisasi memenuhi syarat konsistensi karena error pemotongannya menuju nol untuk $\Delta x \rightarrow 0$ dan $\Delta \mathrm{t} \rightarrow 0$. Jadi, hasil diskritisasi mendekati solusi analitik.

2. Pada simulasi dan interpretasi yang dilakukan pada solusi analitik dan solusi numerik menunjukkan bahwa solusi numerik merupakan solusi pendekatan dari solusi analitik. Perubahan temperatur terjadi secara sama pada solusi analitik dan solusi numerik.

\section{DAFTAR PUSTAKA}

[1]. Durmin. (2013). Studi Perbandingan Perpindahan Panas Menggunakan Metode Beda Hingga dan Cranh-Nicholson. Surabaya: tidak diterbitkan.

[2]. Le, T. P., Q.H., D. T., \& Nguyen, T. (2013). A Backward Parabolic Equation with TimeDependent Coefficient: Regulation and Error Estimates. Journal of Computational and Applied Mathematics, 237 , 432-441.

[3]. Triatmodjo, B. (2002). Metode Numerik Dilengkapi dengan Program Komputer. Yogyakarta: Beta offset.

[4]. Zauderer, E. (2006). Partial Differential Equations of Applied Mathematics. Canada: Wiley. 